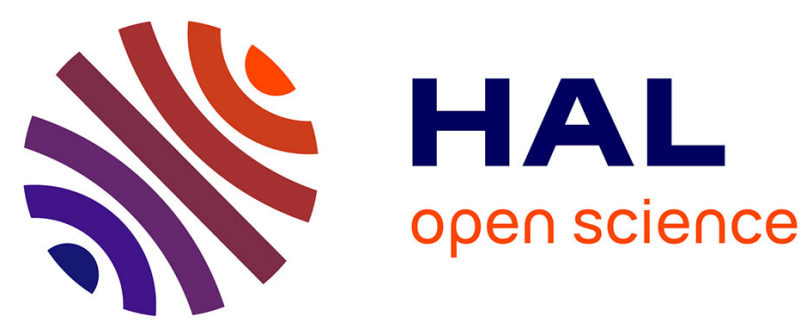

\title{
Experimental and Numerical Thermal Properties Investigation of Cement-Based Materials Modified with PCM for Building Construction Use
}

\author{
Nessrine Essid, Anissa Eddhahak-Ouni, Jamel Neji
}

\section{- To cite this version:}

Nessrine Essid, Anissa Eddhahak-Ouni, Jamel Neji. Experimental and Numerical Thermal Properties Investigation of Cement-Based Materials Modified with PCM for Building Construction Use. Journal of Architectural Engineering, 2020, 26 (3), pp.1-9. 10.1061/(asce)ae.1943-5568.0000399 . hal-02733998

\section{HAL Id: hal-02733998 \\ https://hal.science/hal-02733998}

Submitted on 2 Jun 2020

HAL is a multi-disciplinary open access archive for the deposit and dissemination of scientific research documents, whether they are published or not. The documents may come from teaching and research institutions in France or abroad, or from public or private research centers.
L'archive ouverte pluridisciplinaire HAL, est destinée au dépôt et à la diffusion de documents scientifiques de niveau recherche, publiés ou non, émanant des établissements d'enseignement et de recherche français ou étrangers, des laboratoires publics ou privés. 


\title{
Experimental and Numerical Thermal Properties Investigation of Cement-Based Materials Modified with PCM for Building Construction Use
}

\author{
Nessrine Essid ${ }^{1}$; Anissa Eddhahak-Ouni²; and Jamel Neji ${ }^{3}$
}

\begin{abstract}
Due to their latent heat storage capacity, phase-change materials (PCM) incorporated in wallboards are an effective solution to reduce energy consumption inside buildings. This is achieved by incorporating PCM in construction elements made of cement-based materials. The purpose of this research is to evaluate both the thermal conductivity and the heat storage capacity of mortars and concretes with different amounts of PCM in order to evaluate their thermal performance. Therefore, a laboratory-developed transient plane source experimental setup was used to measure these properties. First, several mortar and concrete specimens including different amounts of PCM $(0 \%, 4.5 \%, 9 \%$, and $13 \%$ by total mass of cement) were manufactured. Then, the experimental setup was used to measure the temperature development on PCM-concretes and PCM-mortars for a period of 1,000 s. The collected data were analyzed to back-calculate the thermal characteristics using a numerical optimization procedure. Numerical findings using the finite-element method show that the testing procedure efficiently provides accurate estimations of the thermal properties of the tested specimens. It was found that cement-based materials incorporating PCM have lower thermal conductivity and higher heat storage capacity, which indicates the improvement of their thermal behavior.
\end{abstract}

Author keywords: Phase-change materials (PCM); Cement-based material; Thermal conductivity; Heat storage capacity; Experimental setup; Optimization; Numerical simulation; Ansys CFX.

\section{Introduction and Literature Review}

In developing countries with high growth rates and improved standards of living, energy consumption and greenhouse gas emissions have significantly increased in recent decades (IEA 2017; Solomon et al. 2007). Thus, nowadays, saving energy and reducing gas emissions are becoming crucial issues and great challenges to industrial and developed countries for the future (IEA 2017).

Approximately $40 \%$ of the world energy was consumed by the construction sector in 2010 (IEA 2017). Indeed, buildings with low thermal mass are subject to overheating and temperature fluctuations. To solve this problem and provide thermal comfort indoors, the use of air conditioning during the summers and heating systems during the winters is necessary (Solomon et al. 2007; Climate Initiative 2005). However, these systems consume huge quantities of energy. Therefore, researchers in the construction sector are working on

${ }^{1}$ Research Assistant, National Engineering School of Tunis, LR11ES16 Laboratory of Materials, Optimization, and Environment for Sustainability, Tunis El Manar Univ., B.P. 37 Le Belvédère, 1002 Tunis, Tunisia (corresponding author). ORCID: https://orcid.org/0000-0001-6365-3568. Email: essid.nessrinegc@gmail.com

${ }^{2}$ Professor, PIMM Laboratory, CNRS UMR 8006, Arts et Métiers ParisTech, 151 bd de 1'Hôpital, 75013 Paris, France. Email: anissaeddhahak@yahoo.fr

${ }^{3}$ Professor, National Engineering School of Tunis, LR11ES16 Laboratory of Materials, Optimization, and Environment for Sustainability, Tunis El Manar Univ., B.P. 37 Le Belvédère, 1002 Tunis, Tunisia. Email: nejhe. improving the thermal performance of building materials in order to reduce the use of electric systems. In fact, developing new efficient alternatives based on environmentally friendly construction materials is needed. Among these alternatives, storing heat and cold for later usage has become a key technology and an attractive solution for building professionals to improve energy efficiency in the building sector (Zalba et al. 2003; Cabeza et al. 2007).

In order to reach smart and light wallboard structures, classic construction materials, such as plaster and concrete, can be combined with those having a high latent heat. The latter have the advantage of absorbing large amounts of energy in a comparatively very small volume (Pasupathy et al. 2008; Sharma et al. 2009). Phase-change materials (PCM), preferably those with solid-liquid transition, have a high latent heat, and therefore a high volumetric storage capacity at low temperature (Kuznik et al. 2011; Banu et al. 1998). This kind of PCM presents melting temperatures within ambient temperature range. Consequently, their integration in construction materials is likely to improve the thermal storage capacity of the building and ultimately contributes to keeping the inside temperature relatively constant with low variations (Cabeza et al. 2011; Devaux and Farid 2017). For instance, incorporation of PCM in a $1.5-\mathrm{cm}$-thick plaster wall resulted in the same thermal storage capacity as a concrete wall that is 9-cm-thick or a brick wall that is 12-cm-thick (Fig. 1).

It is known that the addition of any substance to cement-based materials changes their properties. Wang et al. (2014) investigated the effects of nanomaterials on the hydration kinetics and rheology of ordinary portland cement pastes. The experimental results indicated that the addition of nanolimestone and nanosilica accelerated early cement hydration. More specifically, the maximum heat flow increased by nearly $2 \mathrm{~mW} / \mathrm{g}$ when the nanomaterials increased by $1.5 \%$, whereas the time to reach the heat-flow peaks decreased. Toufigh et al. studied polymer concrete (PC) as a potential replacement for concrete based on ordinary portland cement (OPC) 


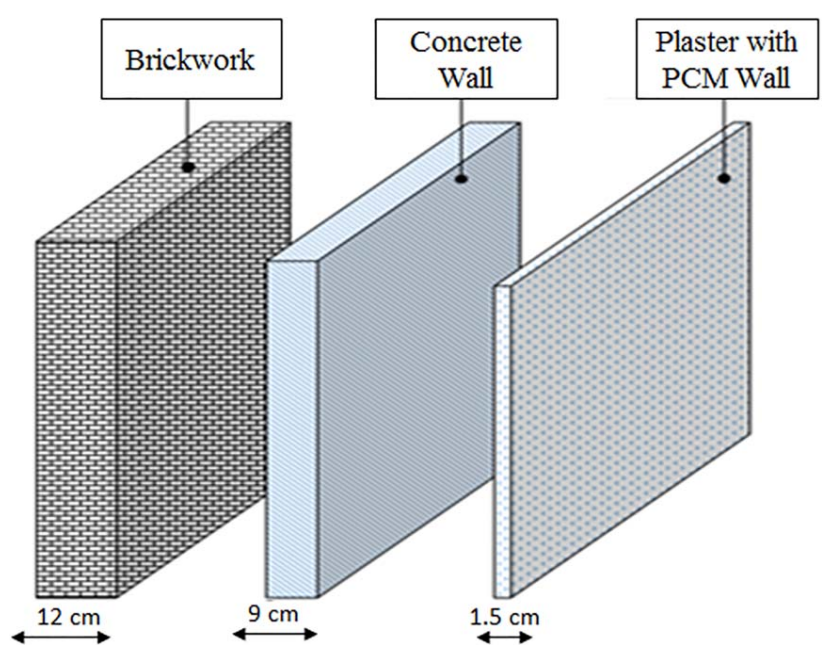

Fig. 1. Comparison of thickness between brickwork, concrete wall, and plaster with PCM wall having the same thermal heat storage.

(Toufigh et al. 2013). The experimental results indicate that the PC and fiber-reinforced polymer concrete (FRPC) specimens exhibit significantly higher compressive and tensile strength compared to OPC. They are also tougher than OPC specimens. FRPC specimens have higher tensile strength and toughness relative to PC specimens, but both sets are comparable in compressive strength (Toufigh et al. 2013).

In our case, there are inherent disadvantages of PCM application in buildings. Indeed, low thermal conductivities of many PCM have posed a continuous challenge. Furthermore, despite the existence of many different phase-change transitions - from solid to solid, from solid to gas, from liquid to gas, or from solid to liquid - the one mainly used is the solid-to-liquid change. Some limitations are related to the other phase-change transitions such as:

- In the case of liquid-to-gas phase change, the thermal storage requires large volumes to store the heat.

- In the case of solid-to-solid phase change, the transformation is too slow and has a low transformation heat (Leppers 2005; Hawes et al. 1992).

The use of PCM in construction applications is also limited by the appearance of some phenomena, such as hysteresis, phase segregation, and supercooling problems (Sharma et al. 2009; Kuznik et al. 2011). Because the use of PCM is still experimental, they are quite expensive.

The use of PCM in buildings has been one of the greatest research topics of the last few decades. PCM are currently classified into three groups: organic PCM, inorganic PCM, and eutectic PCM (Cabeza et al. 2011).

In 2008, Castellon studied PCM effects on air-conditioning usage. He proved that $5 \%$ of consumed energy is saved during the summer period when using only $5 \%$ of PCM in practice.

Despite the numerous advantages of PCM from a thermal point of view, a major mechanical disadvantage is emphasized, mainly the compressive resistance of the construction material decreases due to the increased porosity with addition of PCM. This drawback was noticed in many experimental studies (Hunger et al. 2009; Meshgin and Xi 2012).

Thanks to their important advantages, several types of organic PCM with a large range of melting points have been combined with different construction materials. The main results about their effect on the material properties have been published in many journals (Sharma et al. 2009; Kuznik et al. 2011). However, the behavior of PCM is complex, and their properties are often not easy to measure. For example, the thermal behavior can be affected by the shape, the geometry, the dimensions, and especially the heat transfer mechanism (Meshgin and Xi 2012).

Therefore, studying the amounts of exchanged heat between the material and the surrounding environment is important because it allows planning an optimal control of the thermal energy storage and release. In addition, the measurement of the heat flux and the temperature development is necessary for the design of structures with PCM-cementitious materials. To the authors' best knowledge, very few research works have been devoted to the problem of temperature and heat-flux measurements using representative specimens of PCM-cement-based materials, and much less to large-size materials such as PCM walls. The thermal methodologies most commonly used have often been based on the study of PCM specimens of a few milligrams by thermogravimetric analysis (TGA) or differential scanning calorimetry (DSC) techniques. This can raise questions about the specimens used for measurement with respect to their homogeneity and representativeness. In addition, there is an incompatibility between the needed TGA and DSC specimens' size and the aggregates' dimensions when studying concrete. Hence, this study was carried out in the framework of a wider research program of the authors that deals with a thermal characterization method using a laboratory-developed setup. The experimental procedure allows the determination of the thermophysical properties (thermal conductivity and heat storage capacity) of materials based on simultaneous measurements of heat flux and temperature elevation.

This paper is structured as follows: In the following section, "Materials and Methods," the studied materials, the experimental setup, and the theoretical background of a mathematical approach aiming to measure the thermal conductivity and the specific heat capacity of PCM-cementitious materials are described. The "Results and Discussions" section is devoted to the numerical simulation of the testing setup and compares its results with those found experimentally. Then, in the "Conclusions" section, the obtained results are discussed followed by the main conclusions of the study.

\section{Materials and Methods}

\section{Materials Description}

Phase-Change Materials

The PCM used in this study are commercial products named Micronal DS 5038 (BASF The Chemical Company, Ludwigshafen, Germany) in capsule powder form, with a solid-liquid phase transition. These PCM were chosen in this study because of their organic properties. In fact, unlike inorganic PCM characterized by the presence of supercooling and incongruent melting phenomena, organic PCM have shown good stability in the concrete mixes (Kuznik et al. 2011).

These PCM in their capsule powder form are made with a paraffin core microencapsulated in PMMA polymer shell, forming a thin protective insulating film. The scanning electron microscope (SEM) observations of these PCM, illustrated in Fig. 2, and highlighted in previous studies (Eddhahak-Ouni et al. 2013; Drissi et al. 2015; Drissi 2015), revealed that they generally have a spherical shape with a diameter ranging between 100 and $300 \mu \mathrm{m}$. In reality, these capsules represent the agglomeration of many thousands of microcapsules ranging between 2 and $20 \mu \mathrm{m}$ bounded together. This phenomenon could be explained by the spray drying of the initial PCM solution, which results in the creation of bigger secondary particles for dust prevention and better handling. Some damaged capsules were observed before their incorporation in the concrete/mortar mix. 


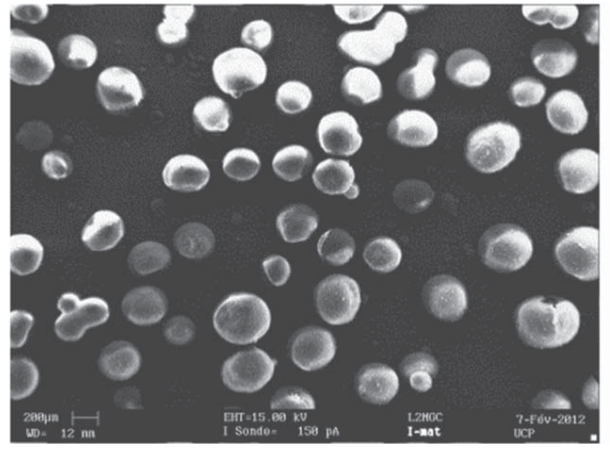

(a)

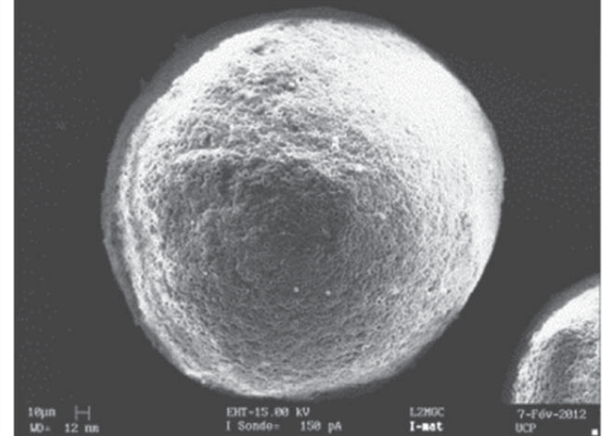

(b)

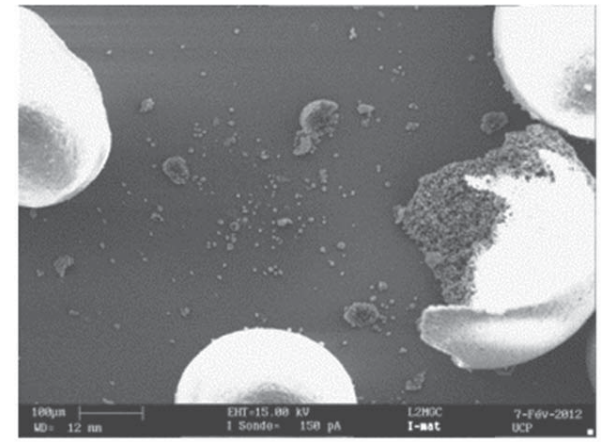

(c)

Fig. 2. SEM observations of PCM capsules: (a) overview; (b) micro-PCM agglomeration; and (c) PCM damage.

According to the technical data sheets of the PCM supplier (BASF 2012), their melting point and phase-change enthalpy are $25^{\circ} \mathrm{C}$ and $110 \mathrm{~kJ} / \mathrm{kg}$, respectively. These values were also checked using DSC technique during the study by Drissi et al. (2015). In addition, measurements by laser flash analysis (LFA) were carried out, showing that PCM present low thermal conductivities with an average value of about $0.155 \mathrm{~W} / \mathrm{m} / \mathrm{K}$ in the temperature range $-10^{\circ} \mathrm{C}$ to $60^{\circ} \mathrm{C}$.

The first dynamic scan was performed by cooling the sample from $20^{\circ} \mathrm{C}$ to $-10^{\circ} \mathrm{C}$, and then an isothermal segment of $5 \mathrm{~min}$ was programmed so that the sample could reach an isothermal equilibrium state. Next, a heating dynamic segment was carried out from $-10^{\circ} \mathrm{C}$ to $55^{\circ} \mathrm{C}$ followed by an isothermal step before cooling the sample from $55^{\circ} \mathrm{C}$ to $-10^{\circ} \mathrm{C}$. This last cooling segment was arranged so that the DSC signal reversibility could be checked. To finish, a heating segment was performed from $-10^{\circ} \mathrm{C}$ to $20^{\circ} \mathrm{C}$. The temperature range of the DSC program was selected to mirror the expected natural climate temperatures. The DSC tests were performed using samples with the same mass $(10 \mathrm{mg})$. For every scanning rate, the test was repeated at least three times, using virgin samples each time. In addition, the DSC experiment was also used to measure the specific heat capacity of PCM.

The DSC results showed that PCM exhibit comparable thermal behavior during heating and cooling processes with an increase of the sensible and latent heats in the exothermic signal. For more details, see the study by Drissi et al. (2015).

\section{Mortar and Concrete Confection}

Different samples of PCM-concretes and PCM-mortars were fabricated in this study. Concrete and mortar specimens with no addition of PCM were also produced to serve as controls. All prepared specimens have a square cross section $\left(4 \times 4 \mathrm{~cm}^{2}\right)$. Two different thicknesses of specimen were considered: $e=2 \mathrm{~cm}$ and $e=4 \mathrm{~cm}$. In order to avoid capsule damage during the mixing process, PCM were incorporated with the mixture at the last stage.

The mortar and concrete formulations considered in the present study are those optimized by the authors in previous works (Drissi 2015). Tables 1 and 2 summarize the quantities for the different ingredients used to manufacture concretes and mortars, respectively.

Portland cement (CEM II/A-L $32.5 \mathrm{~N}$ ), sand (with a particle size distribution between 0 and $250 \mu \mathrm{m}$ ), and a water-to-cement ratio equal to 0.5 were used in this study. Different PCM amounts $(0 \%, 4.5 \%, 9 \%$, and $13 \%)$ by total mass of the cement were used to manufacture the PCM-concretes and PCM-mortars. It can be noticed that the cement volume fractions in the PCM-mortars are respectively the same as the ones in the PCM-concretes.
Table 1. Reference concrete formulation for making $1 \mathrm{~m}^{3}$ of concrete

\begin{tabular}{lc}
\hline Component & Value \\
\hline Cement $(\mathrm{kg})$ & 360 \\
W:C & 0.5 \\
Sand $(\mathrm{kg})$ & 748 \\
Gravel $(\mathrm{kg})$ & 1,076 \\
\hline
\end{tabular}

Note: $\mathrm{W}: \mathrm{C}=$ water-to-cement ratio.

Table 2. Reference mortar formulation

\begin{tabular}{lc}
\hline Component & Value \\
\hline Cement $(\mathrm{g})$ & 500 \\
$\mathrm{~W}: \mathrm{C}$ & 0.5 \\
Sand $(\mathrm{g})$ & 1,038 \\
\hline
\end{tabular}

Note: $\mathrm{W}: \mathrm{C}=$ water-to-cement ratio.

After casting, the samples were placed in a room at a temperature of $22^{\circ} \mathrm{C}$ and a relative humidity of $50 \%$. The specimens were dried inside the laboratory for 28 days and then used for the experiments. Note that the mass of the specimens was monitored before and after the thermal tests, and no significant change was found, thereby showing stable water content during the tests.

\section{Experimental Setup Description}

The classical DSC technique often used for the identification of thermal dynamic properties of materials is not adaptable for the case of PCM-cement-based materials because of the incompatibility of the specimen sizes with the crucible sizes (Devaux and Farid 2017). In order to characterize the thermal properties of PCM-concretes and PCM-mortars using specimens that represent their geometry and microstructure, an original laboratory-developed experimental setup was used (Fig. 3).

The proposed DEsProTherm device designed by EPSILONFAHRENHEIT (certified ISO 9001 version 2008) looks like hotplate setups commonly used for thermal conductivity measurement (Mathis Instruments 2001).

In order to minimize the heat transfer dissipation through the lateral sides of the tested material, a 4-cm thickness of insulation layer with known thermal properties was placed in contact with the lateral surfaces of the specimens. Whereas the lower and upper surfaces of the specimens were put in contact with the two isothermal heat exchange plates of aluminum linked to a heat source (Fig. 4). Heat flux was measured by a thin tangential gradient fluxmeter placed at the interface between the heating element and the specimen. The temperature development was measured by thermocouples placed on the lower and upper surfaces of the specimen. 


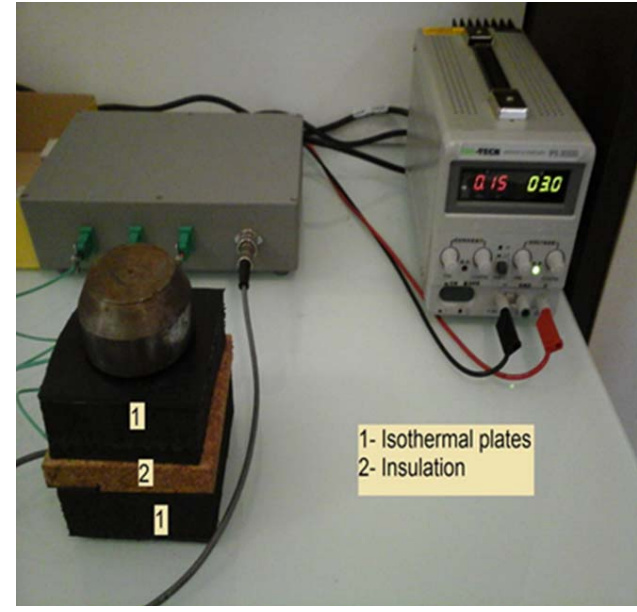

Fig. 3. Experimental setup: material testing. (Image by Nessrine Essid.)

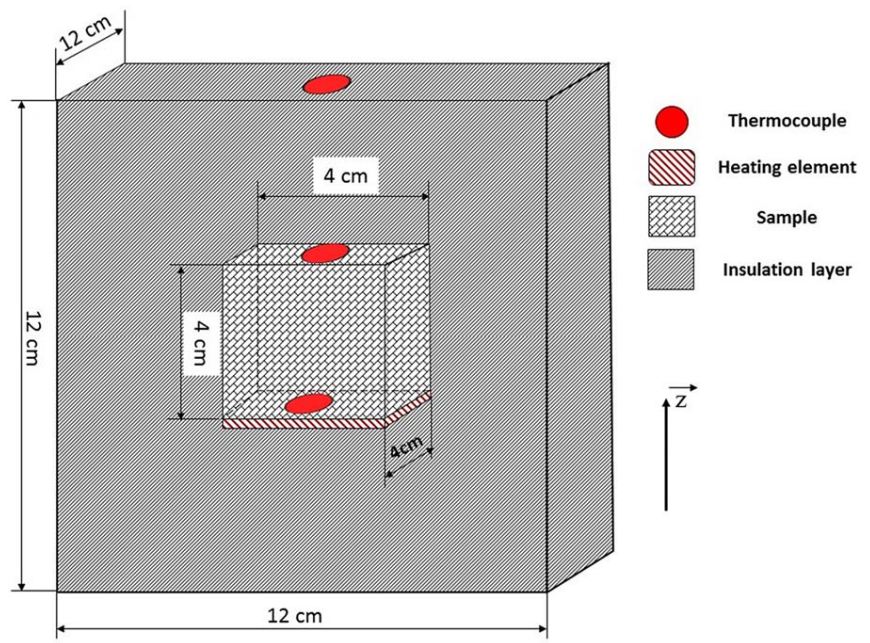

Fig. 4. Schematic description of the experimental setup (crosssectional view).

The DEsProTherm setup measured the temperature elevation when the material was subject to transient heat flux. Then, analysis of the measured temperature over time on the upper and lower surfaces of the specimen allowed the calculation of the volumetric heat storage capacity and the thermal conductivity of the material. The measurement period was set to $1,000 \mathrm{~s}$. All testing was performed at a temperature $\left(\right.$ Troom $\approx 22^{\circ} \mathrm{C}$ ) below the PCM temperature so that PCM were in solid state at the start of the testing.

In the next subsection, the theoretical development used for solving the heat transfer problem in transient regime is presented.

\section{Theoretical Background}

Because the material was insulated on the lateral edges, it is safe to assume a one-dimensional (1D) heat transfer direction into the specimen. Therefore, the mathematical model is based on the transient unidirectional heat conduction phenomenon in a multilayer wall, which can be written as follows (Mathis Instruments 2001):

$$
\frac{\partial T(z, t)}{\partial t}=\frac{\lambda}{\rho C_{p}} \frac{\partial^{2} T(z, t)}{\partial^{2} z}
$$

where $T(z, t)=$ measured temperature; $\lambda=$ thermal conductivity; and $\rho=$ volumetric heat capacity of the considered material.

To solve Eq. (1), it is necessary to specify initial and boundary conditions. The initial condition is

$$
T(z, t=0)=T_{0} \text { for } 0<z<e
$$

The boundary conditions at the sample lower and upper surfaces are

$$
\begin{aligned}
-\lambda\left(\frac{\partial T(z=0, t)}{\partial z}\right) & =\varphi \\
\lambda\left(\frac{\partial T(z=e, t)}{\partial z}\right) & =0
\end{aligned}
$$

where $\varphi=$ imposed heat flux to the material.

Solving Eq. (1) using the conditions [Eqs. (2)-(4)] yields to the analytical temperature expression

$$
\begin{aligned}
T(z, t)= & T_{0}+\frac{\varphi e}{3 \lambda}+\frac{z}{2 \lambda e}(z-2 e) \varphi+\frac{\varphi t}{\rho C_{p} e} \\
& -\frac{2 \varphi e}{\lambda} \sum_{p=1}^{+\infty} \frac{\exp \left(-\left(\lambda / \rho C_{p}\right)(P \pi / e)^{2} t\right)}{(p \pi)^{2}} \cos \left(\frac{p \pi}{e} z\right)
\end{aligned}
$$

Then, one can derive the evolutions versus time of the sample temperature at $z=0$ and $z=e$, respectively given by Eqs. (6) and (7):

$$
\begin{aligned}
\theta\left(0, \lambda, \rho C_{p}, t\right)=T_{0} & +\frac{\varphi e}{3 \lambda}+\frac{\varphi t}{\rho C_{p} e} \\
& -\frac{2 \varphi e}{\lambda} \sum_{p=1}^{N} \frac{\exp \left(-\left(\lambda / \rho C_{p}\right)(P \pi / e)^{2} t\right)}{(p \pi)^{2}} \cos \left(\frac{p \pi}{e} z\right) \\
\theta\left(e, \lambda, \rho C_{p}, t\right)= & T_{0}-\frac{\varphi e}{6 \lambda}+\frac{\varphi t}{\rho C_{p} e} \\
& -\frac{2 \varphi e}{\lambda} \sum_{p=1}^{N}(-1)^{p} \frac{\exp \left(-\left(\lambda / \rho C_{p}\right)(P \pi / e)^{2} t\right)}{(p \pi)^{2}}
\end{aligned}
$$

where $N=$ number of measurements.

The determination of the material thermal conductivity and volumetric heat capacity is obtained by solving the system of Eqs. (6) and (7), in order to find the best fit for the measured temperature development denoted $T_{\text {exp. }}$. For this purpose, an objective function $J$ is given by the following equation and minimized using the leastsquares method:

$$
J=\sum_{k=1}^{k=N}\left\|T_{\exp }\left(e, t_{k}\right)-T\left(e, t_{k}\right)\right\|^{2}
$$

\section{Numerical Simulation of the Samples' Thermal Behavior and Comparison with the Experimental Results}

The specimens' thermal behavior was simulated using the Ansys CFX 15 software. Ansys is a transient system simulation program that simulates the thermal behavior of physical systems. The heat equation is then solved by a finite volumes method that makes it possible to calculate the temperature at each node.

Before developing the equations that govern the heat transfer process occurring in the system, some assumptions were made in order to simplify its solving process. These assumptions are that

- Thermal properties are constant with respect to temperature.

- End effects are neglected.

- Interfacial resistances are negligible. 
- Heat transfer through the wall is assumed 1D.

- Inducted buoyancy flow in the melted PCM is neglected.

Fig. 5 shows the physical system studied in the present work. It consists of a geometry made with a specific material (mortar, PCM-mortar, concrete, PCM-concrete) with homogenous properties. The total thickness of the geometry is either $2 \mathrm{~cm}$ or $4 \mathrm{~cm}$. Its corresponding properties are the results given by the mathematical model studied in the "Materials and Methods" section. The sample was initially at a uniform temperature close to the thermal comfort requirement, $T(z, 0)=T 0=22^{\circ} \mathrm{C}$. The boundary conditions on the outer surfaces are due to the flux variation. The lateral surfaces are adiabatic.

This problem is mathematically expressed by the following equations:

$$
\begin{gathered}
\frac{\partial T(z, t)}{\partial t}=\frac{\lambda}{\rho C_{p}} \frac{\partial^{2} T(z, t)}{\partial z^{2}} ; z \in[0, e], t>0 \\
-\lambda \frac{\partial T}{\partial z}=\varphi ; \quad z=0, t>0 \\
\lambda \frac{\partial T}{\partial z}=0 ; \quad z=e, t>0 \\
T(z, 0)=T_{0} ; z \in[0, e]
\end{gathered}
$$

After optimizing the finite mesh and the time step and after validating the model, the different studied cases were simulated using Ansys software. The total time was $1,000 \mathrm{~s}$, and the time step was

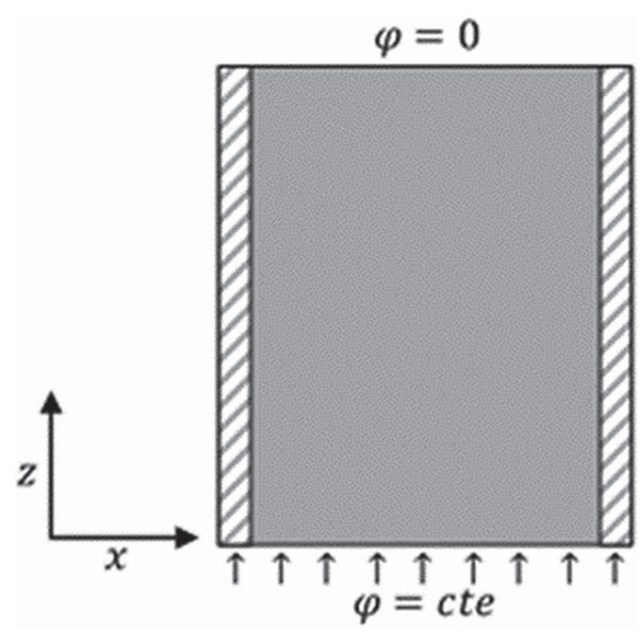

Fig. 5. The studied system.
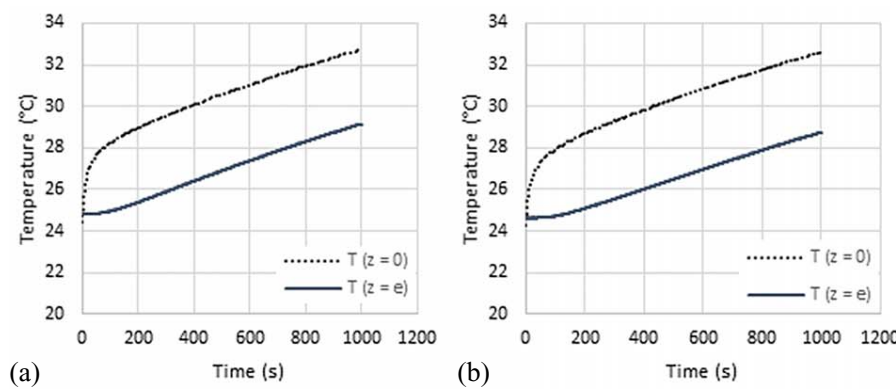

$0.1 \mathrm{~s}$. For samples with $2 \mathrm{~cm}$ thickness, the flow at $z=0$ was taken around $265 \mathrm{~W} / \mathrm{m}^{2}$, while for samples with $4 \mathrm{~cm}$ thickness, it was about $1,180 \mathrm{~W} / \mathrm{m}^{2}$.

\section{Results and Discussions}

This section presents the main results obtained by the DEsProTherm experimental setup, as well as the results of the optimization procedure used for the thermal properties calculation. The sampling frequency of readings was $0.1 \mathrm{~s}$, and the readings were recorded continuously.

\section{Experimental Results (Thermograms)}

Fig. 6 presents the measured temperature over time on the lower $(z=0)$ and upper $(z=e)$ surfaces of the control and PCM-concrete specimens with a thickness of $2 \mathrm{~cm}$. Similarly, Fig. 7 shows the collected data for the control and PCM-mortar specimens with a thickness of $2 \mathrm{~cm}$.

\section{Thermophysical Properties}

The objective function minimization given by Eq. (8) allows the computation of the thermophysical properties (thermal conductivity and volumetric heat storage capacity) of PCM at $T=22^{\circ} \mathrm{C}$. The results are summarized in Figs. 8 and 9 for the 2-cm- and 4-cm-thick concrete specimens, respectively. The symbols at the top of each bar in Figs. 8-11 are indicators of the data. These figures show that addition of PCM in concrete and mortar results in a decrease of thermal conductivity and an increase of the energy storage capacity. These results are in agreement with those found in the literature (Leppers 2005; Meshgin and Xi 2012).

It is also noticed that the decrease of the thermal conductivity is more important for the cubic PCM-concrete specimens with 4-cm thickness, than for the thinner specimens (2-cm thickness). This phenomenon can probably be attributed to the lower thermal diffusivity of cubic samples, in comparison with the thinner concrete ones.

Moreover, an increase of about $15 \%$ was noticed in the volumetric heat storage capacity with $13 \%$ of PCM for a specimen thickness of $2 \mathrm{~cm}$, whereas, an enhancement of only $9 \%$ was found for the specimen thickness of $4 \mathrm{~cm}$. This difference could be explained by many causes including the presence of more damaged PCM particles and consequently more pores found in the 4-cm-hick specimen.

For the control concrete specimens, the specific heat was slightly lower for the thicker one. This small difference could be attributed to the margin of error of the experimental measurements. For the concrete with $9 \%$ PCM specimens, the results seem to be
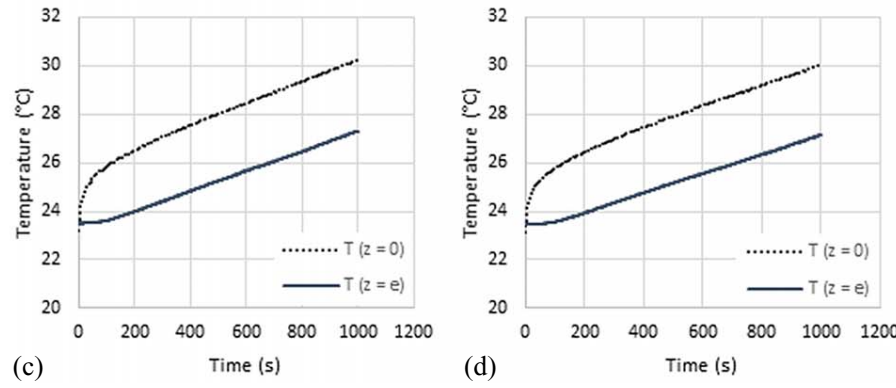

Fig. 6. Temperature evolutions recorded by the experimental setup (PCM-concretes, $e=2 \mathrm{~cm}$ ): (a) 0\% PCM; (b) 4.5\% PCM, (c) 9\% PCM; and (d) $13 \%$ PCM. 


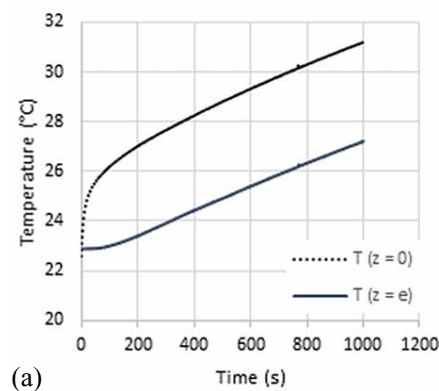

(a)

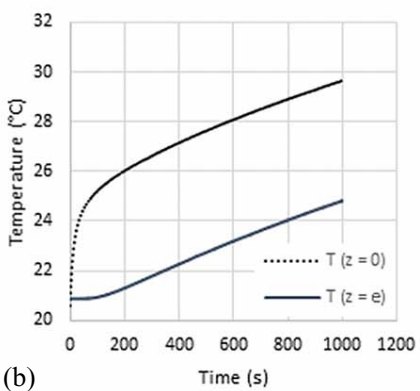

(b)
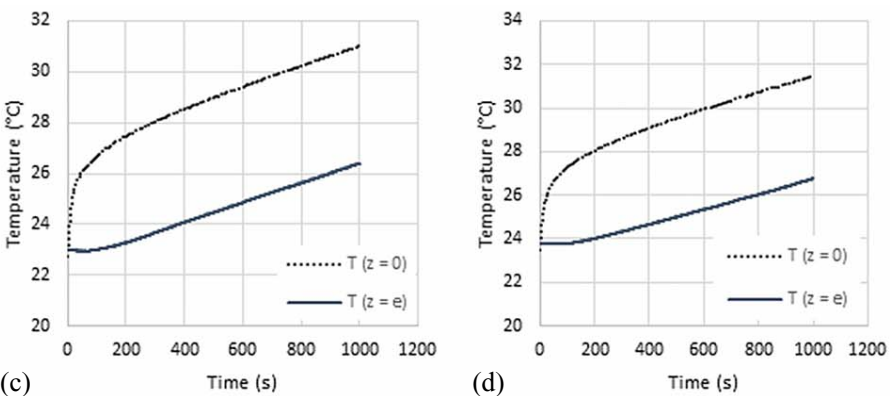

PCM.
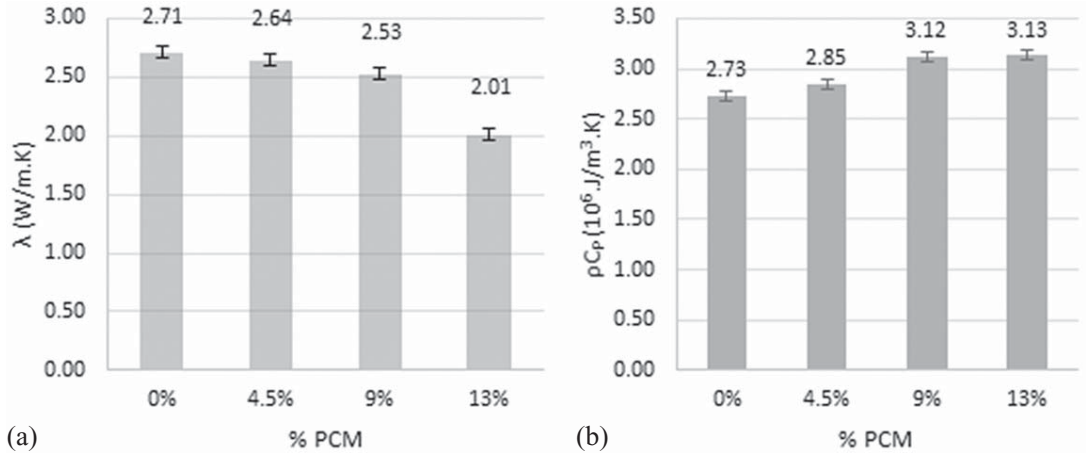

Fig. 8. Thermal properties of PCM-concretes $(e=2 \mathrm{~cm})$ : (a) thermal conductivity; and (b) volumetric heat capacity.
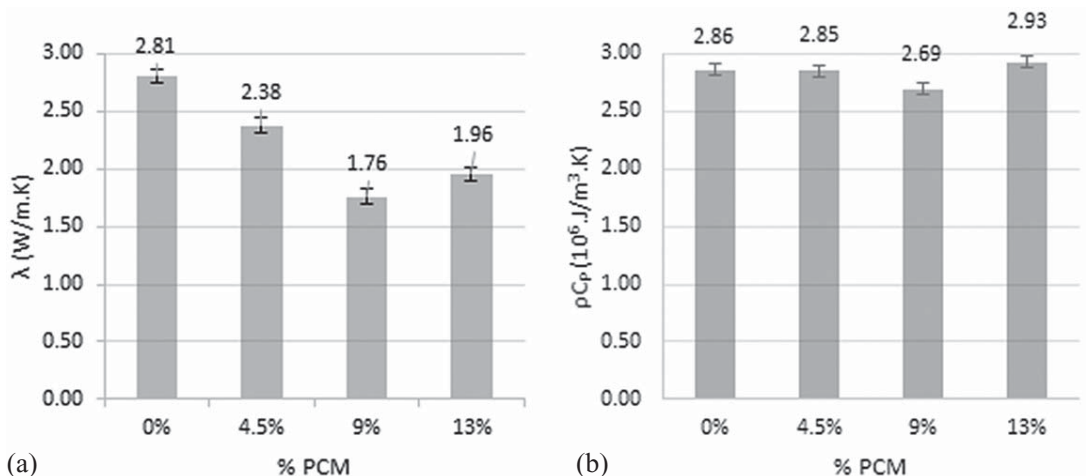

Fig. 9. Thermal properties of PCM-concretes $(e=4 \mathrm{~cm})$ : (a) thermal conductivity; and (b) volumetric heat capacity.

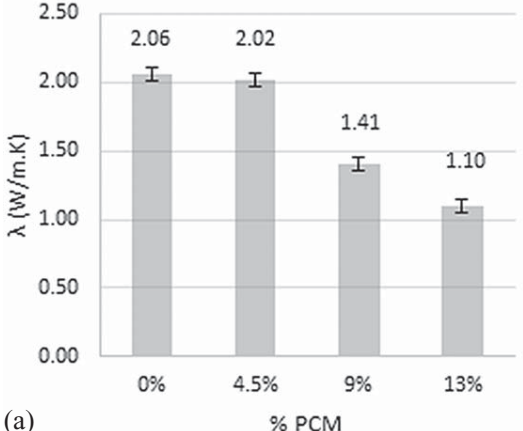

(a)

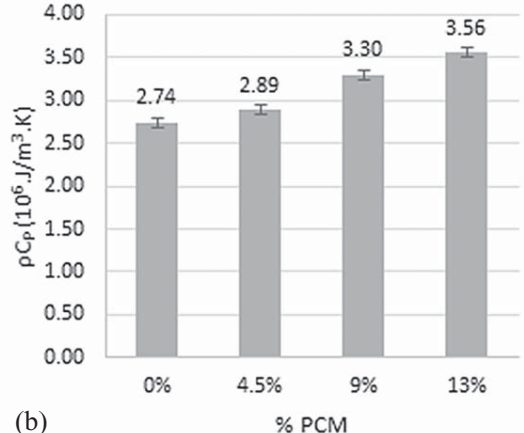

(b)

Fig. 10. Thermal properties of PCM-mortars $(e=2 \mathrm{~cm})$ : (a) thermal conductivity; and (b) volumetric heat capacity. 
irregular, which could also be attributed to the uncertainties of the experimental measurements.

Fig. 10 plots the results of the thermal conductivity and the volumetric heat storage capacity for the PCM-mortar specimens with a thickness of $2 \mathrm{~cm}$. The results of PCM-mortar specimens with a thickness of $4 \mathrm{~cm}$ are represented in Fig. 11.

For the mortar specimens, a significant decrease in the thermal conductivity and a good improvement of the specific heat capacity are noted. Moreover, the effect of the PCM addition seems to be higher in the mortar case than in the concrete case. In the case of the cubic specimen $(e=4 \mathrm{~cm})$, the decrease of thermal conductivity reaches $37 \%$ for PCM-mortars, whereas it is about $30 \%$ for PCM-concretes. However, the increase of the heat capacity was estimated at $13 \%$ for PCM-mortars versus $9 \%$ for PCM-concretes. This result could be explained by the presence of gravel in concrete, which may have influenced the heat transfer process and created more pores in the microstructure of the concrete compared with the mortar. In addition, during the mixture phase, the contact between the PCM and the gravel damaged the PCM-microcapsules; thus, their effect on the thermal properties of concrete was lower than in the mortar. Accordingly, the different aspects linked to the PCM damage and its effect on the long-term energy efficiency of the PCM-concrete final product merit further study in the future in order to improve our understanding and knowledge of the sustainability of PCM-concrete technology.

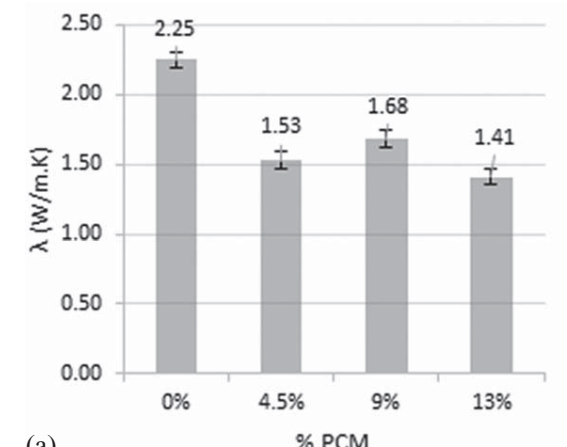

(a)

\section{Discussion of PCM Effect}

As presented previously, a numerical investigation of the thermal behavior of both concrete and PCM-concrete specimens was performed. In addition, the heat equations were solved analytically using MATLAB software package (MathWorks, Natick, MA). This section presents a comparison between the measured temperature development and those predicted using the Ansys model and analytically. For example, Fig. 12 shows the temperature development at the upper surface $(z=e)$ as obtained with the three methods (measured, Ansys model, and analytical). A perfect agreement is achieved among the cases.

The temperature difference $(\Delta T)$ between the upper and lower surfaces of the specimens is an important indicator of the performance of PCM. In order to evaluate this parameter correctly, a normalization was performed on the temperature data. Fig. 13 shows the results from the measured temperature and from the numerically predicted ones for the four treated PCM rates $(0 \%, 4.5 \%, 9 \%$, and $13 \%$ ) in the case of concrete specimens with a thickness of $e=2 \mathrm{~cm}$. It can be seen that the temperature rise on the upper surface, $z=e$, decreases as the PCM is incorporated. Indeed, the PCM is considered a condenser for the temperature propagation. Thus, about $15 \%$ reduction is noticed for $13 \%$ of PCM in the case of $e=2 \mathrm{~cm}$. These results are coherent with the expected thermal conductivity reduction with the PCM addition. Moreover, the numerical results are very close to the experimental ones (maximum

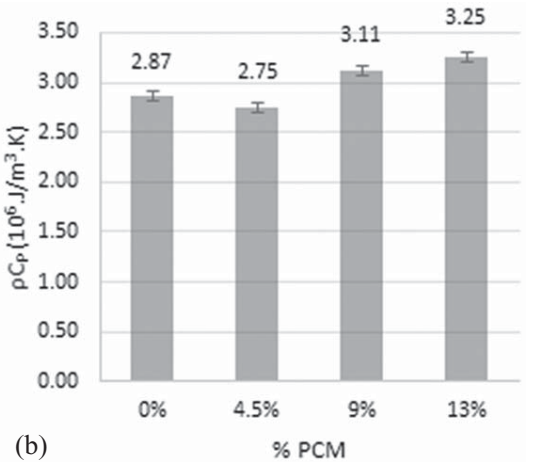

Fig. 11. Thermal properties of PCM-mortars $(e=4 \mathrm{~cm})$ : (a) thermal conductivity; and (b) volumetric heat capacity.

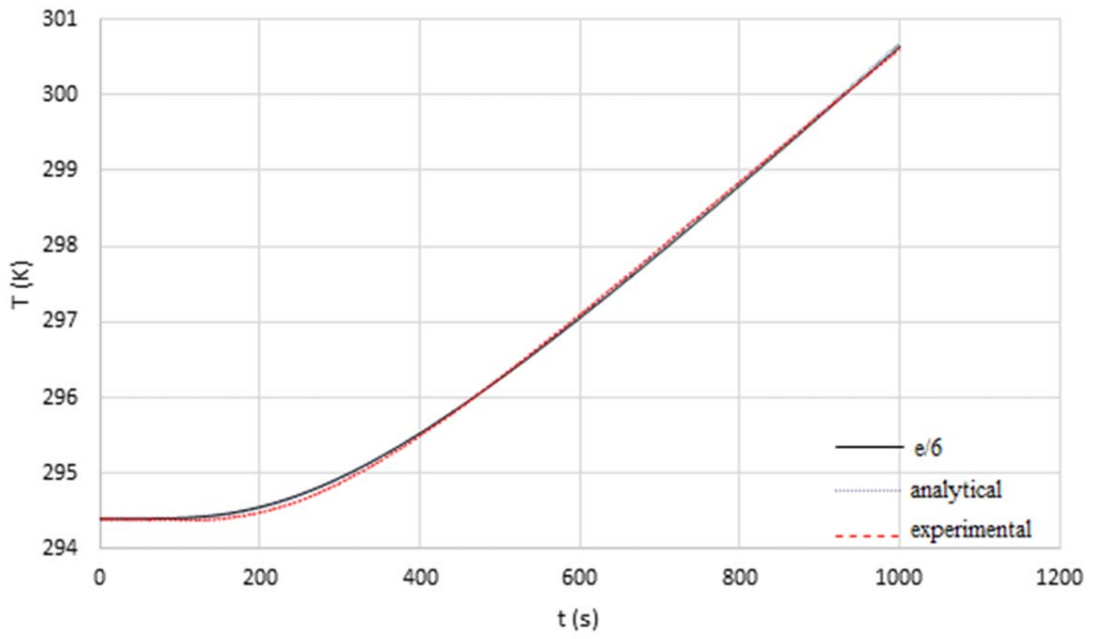

Fig. 12. Comparison of numerical, analytical, and experimental thermograms of temperature on the upper surface. 


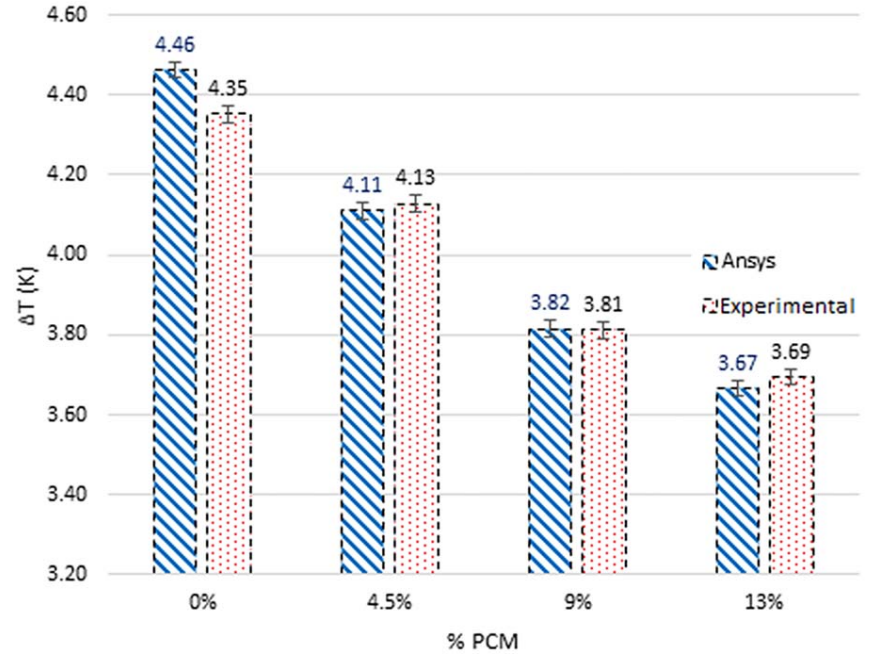

Fig. 13. Temperature rise of the upper face for PCM-concrete $(e=$ $2 \mathrm{~cm})$.

deviation of $2.5 \%$ and minimum deviation of $0.3 \%$ as compared with the experiment).

\section{Conclusions}

In this work, an experimental investigation of smart cement-based materials incorporating PCM using an original laboratory setup are presented. The purpose of the study was to evaluate both the thermal conductivity and the heat storage capacity of mortars and concretes, including different PCM proportions. Based on the transient plane source theory, the experimental setup enabled monitoring of the temperature development on the material specimen subjected to a unidirectional heat flux signal.

Using the measured temperature development on the specimen faces and the analytical temperature solution of the heat transfer problem, thermal conductivity, and heat storage capacity of the tested material are identified. The research results highlight the effects of PCM on the thermal behavior of cement-based material. More specifically, a decrease of the thermal conductivity and an improvement of the heat storage capacity were noticed in both mortar and concrete cases with the addition of PCM. For cubic specimens, the maximal loss of thermal conductivity was evaluated at $30 \%$ with PCM-concretes versus $37 \%$ for the case of PCM-mortars. On the other hand, the maximal gain in the specific heat for PCM-concrete was about $2 \%$ versus $13 \%$ for PCM-mortar. Although the same PCM volume proportions were considered for mortars and concretes, the effect of PCM in the mortar case was greater than that in the concrete case. This finding can be explained by the presence of aggregates in the concrete case. In fact, the concrete specimens are more porous because of the presence of interfacial transition zones around the gravel particles. This can be attributed to the progressive departure of water during the drying process and therefore the creation of voids. Further study is necessary in order to check the variation of the porosity of the concrete with the addition of PCM.

These findings successfully demonstrate not only the efficiency of the developed test bench to evaluate the thermal conductivity and specific heat of materials using relatively large specimens, but also the effect of PCM addition to provide important advantages for thermal storage systems and heat transfer applications.
In the future, it would be interesting to make use of the obtained experimental results in this study to validate a numerical finiteelement model that has been already developed in a previous study (Drissi et al. 2015). The numerical simulation allows a fast prediction of the PCM-cement-based material's thermal response at a macroscale when subjected to complex scenarios of extreme ambient temperatures. Moreover, in order to determine the effect of those materials on the thermal comfort of a building, it is necessary to study numerically and experimentally other wall thicknesses and other amounts of PCM to incorporate with the cement-based material. The arrangement (number, positions, etc.) of the PCM walls in the building could thus be judiciously determined. The construction of a test cell would also help to understand the actual contribution of these walls.

\section{Acknowledgments}

The authors gratefully acknowledge the scientific collaboration of the I2M team from ENSAM-Bordeaux and especially Mr. Denis Bruneau and Mr. Awarou Waste Aregba.

\section{Notation}

The following symbols are used in this paper:

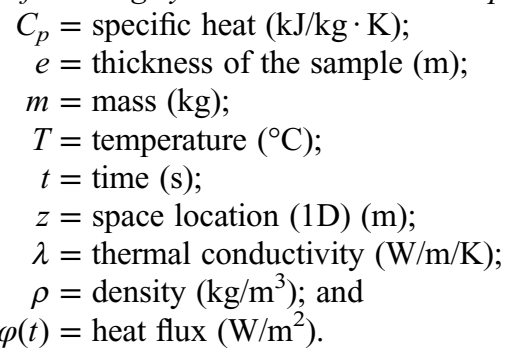

\section{References}

Banu, D., D. Feldman, and D. Hawes. 1998. "Evaluation of thermal storage as latent heat in phase change material wallboard by differential scanning calorimetry and large scale thermal testing." Thermochim. Acta 317 (1): 39-45. https://doi.org/10.1016/S0040-6031(98)00368-2.

BASF. 2012. MCP micronal DS 5038 X, polymer dispersions for construction, provisional technical information. Germany, IL: BASF.

Cabeza, L. F., A. Castell, C. Barreneche, A. de Gracia, and A. I. Fernández. 2011. "Materials used as PCM in thermal energy storage in buildings: A review." Renewable Sustainable Energy Rev. 15 (3): 1675-1695. https://doi.org/10.1016/j.rser.2010.11.018.

Cabeza, L. F., C. Castellón, M. Nogués, M. Medrano, R. Leppers, and O. Zubillaga. 2007. "Use of microencapsulated PCM in concrete walls for energy savings." Energy Build. 39 (2): 113-119. https://doi .org/10.1016/j.enbuild.2006.03.030.

Climate Initiative. 2005. "Buildings and climate change." Accessed September 5, 2018. http://admin.indiaenvironmentportal.org.in/files /SBCI-BCCSummary.pdf.

Devaux, P., and M. M. Farid. 2017. "Benefits of PCM underfloor heating with PCM wallboards for space heating in winter." Appl. Energy 119: 593-602. https://doi.org/10.1016/j.apenergy.2017.01.060.

Drissi, S. 2015. "Development of new concrete 'energy accumulator': Experimental, probabilistic and numerical study of its thermal behavior." Thesis. Dept. of Civil Engineering ESTP-Paris, ENIT-Tunis.

Drissi, S., A. Eddhahak, J. Neji, and S. Care. 2015. "Thermal analysis by DSC of phase change materials, study of the damage effect." J. Build. Eng. 1: 13-19. https://doi.org/10.1016/j.jobe.2015.01.001. 
Eddhahak-Ouni, A., S. Drissi, J. Colin, J. Neji, and S. Care. 2013. "Experimental and multi-scale analysis of the thermal properties of portland cement concretes embedded with microencapsulated phase change materials (PCMs)." Appl. Therm. Eng. 64 (1-2): 32-39. https://doi.org/10.1016/j.applthermaleng.2013.11.050.

Hawes, D. W., D. Banu, and D. Feldman. 1992. "The stability of phase change materials in concrete." Sol. Energy Mater. Sol. Cells 27 (2): 103-118. https://doi.org/10.1016/0927-0248(92)90113-4.

Hunger, M., A. G. Entrop, I. Mandilaras, H. J. H. Brouwers, and M. Founti. 2009. "The behavior of self-compacting concrete containing microencapsulated phase change materials." Cem. Concr. Compos. 31 (10): 731-743. https://doi.org/10.1016/j.cemconcomp.2009.08.002.

IEA (International Energy Agency). 2017. " $\mathrm{CO}_{2}$ emissions from fuel combustion highlights (2017 edition).” Paris: IEA. Accessed September 7, 2018. https://www.iea.org/publications/freepublications/publication /CO2EmissionsfromFuelCombustionHighlights2017.pdf.

Kuznik, F., D. David, K. Johannes, and J. J. Rous. 2011. "A review on phase change materials integrated in building walls." Renewable Sustainable Energy Rev. 15 (1): 379-391. https://doi.org/10.1016/j .rser.2010.08.019.

Leppers, R. 2005. Development of smart microencapsulated organic phase-change materials for enhancing heat storage capacities of concrete. WP4: Design and construction of concrete (concrete compositions). Intron Rep. R20040092. Lleida, Spain: University of Lleida.

Mathis Instruments. 2001. Hot disk thermal constants analyzer instruction manual. Fredericton, NB, Canada: Mathis Instruments
Meshgin, P., and Y. Xi. 2012. "Effect of phase-change materials on properties of concrete." ACI Mater. J. 109: 71-80.

Pasupathy, A., L. Athanasius, R. Velraj, and R. V. Seeniraj. 2008. "Experimental investigation and numerical simulation analysis on the thermal performance of a building roof incorporating phase change material (PCM) for thermal management." Appl. Therm. Eng. 28 (5-6): 556-565. https://doi.org/10.1016/j.applthermaleng.2007.04.016.

Sharma, A., V. V. Tyagi, C. R. Chen, and D. Buddhi. 2009. "Review on thermal energy storage with phase change materials and applications." Renewable Sustainable Energy Rev. 13 (2): 318-345. https://doi.org/10 .1016/j.rser.2007.10.005.

Solomon, S., D. Qin, M. Manning, Z. Chen, M. Marquis, K. B. Averyt, M. Tignor, and H. L. Miller. 2007. Contribution of working group I to the fourth assessment report of the intergovernmental panel on climate change. Cambridge, UK: Cambridge University Press.

Toufigh, V., H. Saadatmanesh, and S. Ahmari. 2013. "Strength evaluation and energy-dissipation behavior of fiber-reinforced polymer concrete." $A d v$. Civ. Eng. Mater. 2 (1): 622-636. https://doi.org/10.1520/ACEM20130074.

Wang, X., K. Wang, J. Tanesi, and A. Ardani. 2014. "Effects of nanomaterials on the hydration kinetics and rheology of portland cement pastes." Adv. Civ. Eng. Mater. 3 (2): 142-159. https://doi.org/10.1520 /ACEM20140021.

Zalba, B., J. M. Marin, L. F. Cabeza, and H. Mehling. 2003. "Review on thermal energy storage with phase change material: Heat transfer analysis and applications." Appl. Therm. Eng. 23 (3): 251-283. https://doi .org/10.1016/S1359-4311(02)00192-8. 